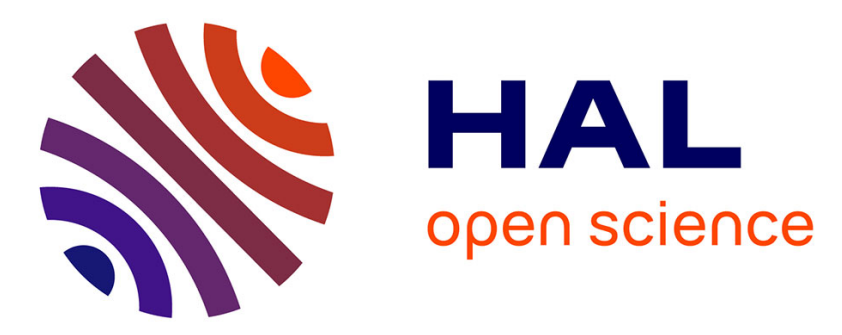

\title{
Startle response of captive North Sea fish species to underwater tones between 0.1 and $64 \mathrm{kHz}$
}

Ronald A. Kastelein, Sander van Der Heul, Willem C. Verboom, Nancy

Jennings, Jan van Der Veen, Dick de Haan

\section{- To cite this version:}

Ronald A. Kastelein, Sander van Der Heul, Willem C. Verboom, Nancy Jennings, Jan van Der Veen, et al.. Startle response of captive North Sea fish species to underwater tones between 0.1 and 64 kHz. Marine Environmental Research, 2008, 65 (5), pp.369. 10.1016/j.marenvres.2008.01.001 . hal00501935

\section{HAL Id: hal-00501935 \\ https://hal.science/hal-00501935}

Submitted on 13 Jul 2010

HAL is a multi-disciplinary open access archive for the deposit and dissemination of scientific research documents, whether they are published or not. The documents may come from teaching and research institutions in France or abroad, or from public or private research centers.
L'archive ouverte pluridisciplinaire HAL, est destinée au dépôt et à la diffusion de documents scientifiques de niveau recherche, publiés ou non, émanant des établissements d'enseignement et de recherche français ou étrangers, des laboratoires publics ou privés. 


\section{Accepted Manuscript}

Startle response of captive North Sea fish species to underwater tones between 0.1 and $64 \mathrm{kHz}$

Ronald A. Kastelein, Sander van der Heul, Willem C. Verboom, Nancy Jennings, Jan van der Veen, Dick de Haan

PII:

S0141-1136(08)00005-6

DOI: 10.1016/j.marenvres.2008.01.001

Reference: MERE 3163

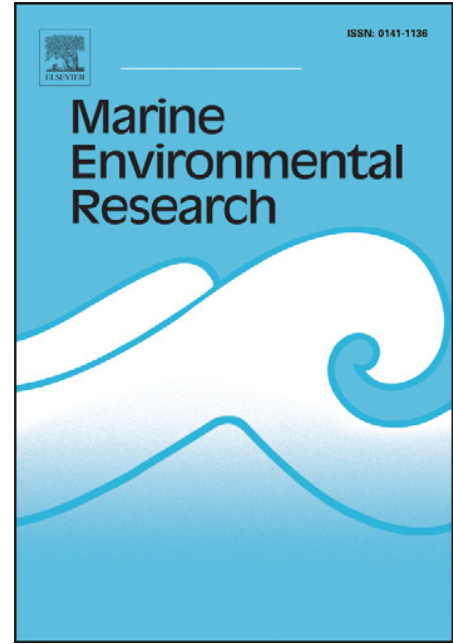

To appear in:

Marine Environmental Research

Received Date:

7 September 2007

Revised Date:

7 January 2008

Accepted Date:

8 January 2008

Please cite this article as: Kastelein, R.A., van der Heul, S., Verboom, W.C., Jennings, N., van der Veen, J., de Haan, D., Startle response of captive North Sea fish species to underwater tones between 0.1 and $64 \mathrm{kHz}$, Marine Environmental Research (2008), doi: 10.1016/j.marenvres.2008.01.001

This is a PDF file of an unedited manuscript that has been accepted for publication. As a service to our customers we are providing this early version of the manuscript. The manuscript will undergo copyediting, typesetting, and review of the resulting proof before it is published in its final form. Please note that during the production process errors may be discovered which could affect the content, and all legal disclaimers that apply to the journal pertain. 


\title{
Startle response of captive North Sea fish species to underwater tones between 0.1 and $64 \mathrm{kHz}$
}

Ronald A. Kastelein ${ }^{\mathrm{a}^{*}}$, Sander van der Heul ${ }^{\mathrm{a}}$, Willem C. Verboom ${ }^{\mathrm{b}}$, Nancy Jennings ${ }^{\mathrm{c}}$, Jan van der Veen ${ }^{\mathrm{d}}$, and Dick de Haan ${ }^{\mathrm{e}}$

${ }^{a}$ Sea Mammal Research Company (SEAMARCO), Julianalaan 46, 3843 CC Harderwijk, The Netherlands

${ }^{b}$ TNO Observation Systems, P.O. Box 96864, 2509JG Den Haag, The Netherlands

${ }^{c}$ Dotmoth, 1 Mendip Villas, Crabtree Lane, Dundry, Bristol BS41 8LN, United Kingdom

${ }^{d}$ Sea aquarium "het Arsenaal", Arsenaalplein 1, 4381 BL Vlissingen, The Netherlands

${ }^{\mathrm{e}}$ Institute for Marine Resources \& Ecosystem Studies (IMARES), P.O. Box 68, 1970 AB IJmuiden, The Netherlands

*Corresponding author. Tel.: + 31-341-456252; fax: +31-341-456732.

E-mail address: researchteam@zonnet.nl (R.A. Kastelein).

\begin{abstract}
World-wide, underwater background noise levels are increasing due to anthropogenic activities. Little is known about the effects of anthropogenic noise on marine fish, and information is needed to predict any negative effects. Behavioural startle response thresholds were determined for eight marine fish species, held in a large tank, to tones of 0.1-64 kHz. Response threshold levels varied per frequency within and between species. For sea bass, the $50 \%$ reaction threshold occurred for signals of $0.1-0.7 \mathrm{kHz}$, for thicklip mullet $0.4-0.7 \mathrm{kHz}$, for pout $0.1-0.25 \mathrm{kHz}$, for horse mackerel $0.1-2 \mathrm{kHz}$ and for Atlantic herring $4 \mathrm{kHz}$. For cod, pollack and eel, no $50 \%$ reaction thresholds were reached. Reaction threshold levels increased from $\sim 100 \mathrm{~dB}$ (re $1 \mu \mathrm{Pa}$, rms) at $0.1 \mathrm{kHz}$ to $\sim 160 \mathrm{~dB}$ at $0.7 \mathrm{kHz}$. The $50 \%$ reaction thresholds did not run parallel to the hearing curves. This shows that fish species react very differently to sound, and that generalisations about the effects of sound on fish should be made with care. As well as on the spectrum and level of anthropogenic sounds, the reactions of fish probably depend on the context (e.g. location, temperature, physiological state, age, body size, and school size).
\end{abstract}


Key words: Acoustics; Atlantic herring; behaviour; Atlantic cod; common eel; horse mackerel; marine fish; pollack; pout; sea bass; thicklip mullet

\section{Introduction}

World-wide, underwater background noise levels are increasing due to anthropogenic activities (National Research Council, 2003; 2005). Many marine organisms rely heavily on acoustics to survive. Fish, for instance, engage with their surroundings through sound, by using species-specific acoustic adaptations for hunting, territorial behaviour, mate attraction, spatial orientation, predator aversion, etc (Popper et al., 2003). Such ecologically important behaviours can be negatively influenced by anthropogenic noise. Little is known about the effects of anthropogenic noise on marine fish, and much information is needed to evaluate or predict any negative effects (Popper et al., 2004).

The effect of a sound may depend on: 1) properties of the sound, such as frequency spectrum, source level (SL), duration, rise and fall times in level, and repetition rate, 2) background noise (masking), 3) sound level, duration and spectrum of the sound as received by the animal, 4) hearing properties of the species (sensitivity, directivity index and critical ratio), and 5) species-specific or individual variation in reaction to sound.

Limited information is available on the hearing sensitivity of only about 100 of the 27,000 marine fish species (Popper et al., 2003). Most audiograms of marine fish species indicate that their highest sensitivity to sounds falls within the $0.1-2 \mathrm{kHz}$ range. The fact that the bandwidth of hearing sensitivity is narrow could be due to mechanical limitations of the sense organs, which may include the swim bladder, or to physical constraints of the testing systems (Ladich and Popper, 2004). However, some studies suggest that clupeid fish may also be able to detect ultrasound (Mann et al., 2002) although Pacific herring cannot (Mann et al., 2005). Cod can detect ultrasound ( $3 \mathrm{~ms} 38 \mathrm{kHz}$ pulses), but only at very high received levels (of > $194 \mathrm{~dB}$ re $1 \mu \mathrm{Pa}$; Astrup and Møhl, 1993; 1998).

The fact that a fish can detect a sound does not necessarily mean that it will react to that sound. In many species, a certain sound pressure level needs to be reached before the behaviour is affected, and some fish species do not show startle responses to sounds no matter how loud they are. Researchers have investigated the effects of specific sounds on the behaviour of marine fish species, and responses vary greatly (Moulton and Backus, 1955; Hawkins, 1986; Myrberg, 1990; Popper and Carlson, 1998; Luczkovich et al., 2000; Kastelein et al., 2005).

The aim of the present study was to determine the behavioural reaction threshold levels of eight fish species from the North Sea to pure tones in the frequency range 0.1 to 64 $\mathrm{kHz}$. Where possible, we compare our thresholds to hearing thresholds, and evaluate the relationship between sound detection and response. Though pure tones may not occur often in nature, an understanding of the responses of fish species to them is fundamental to understanding their responses to more complex sounds, which could be tested in applied follow-up studies.

\section{Materials and methods}

\subsection{Study animals}

Eight fish species that are found in the North Sea were selected for testing, based on their economic importance in fisheries, their availability, their ease of maintenance in captivity, and the temperatures at which they can be kept (the water temperature in our study tank was influenced by the environment). The animal welfare commission of the Netherlands 
stipulated that the fish used must feed readily in captivity, so they had to come from aquaria or fish farms, though most were originally wild-caught. All came from the Netherlands. Six of the study species [sea bass (Dicentrarchus labrax), thicklip mullet (Chelon labrosus), pout (Trisopterus luscus), Atlantic cod (Gadus morhua), pollack (Pollachius pollachius) and horse mackerel (Trachurus trachurus)] were from Sea aquarium "Het Arsenaal", Flushing (Table 1). The fish had been wild-caught by hook and line or in a trap, so that no obvious damage had occurred to their swim bladders. The common eel (Anguilla anguilla) came from "Schot aquacultuur" fish farm, Bruinisse. The Atlantic herring (Clupea harengus) were borrowed from the Oceanium department of Blijdorp Zoo, Rotterdam. The fish were all adapted to captivity and were feeding voluntarily.

Except for the Atlantic herring, the animals were fed $a d$ lib. on pieces of raw fish (food was given until the animals stopped eating) twice a week after the daily study sessions. The herring were fed Trouvit pellets (Nutreco Aquaculture) from a food dispenser throughout the day. The amount eaten was related to the water temperature. For one to two weeks before each species was tested, the fish were kept in white polyester $2.2 \mathrm{~m}$ diameter holding tanks with a water depth of $1 \mathrm{~m}$. These tanks were very quiet, as they (and their water systems) had been designed specifically for acoustic research. In the holding tanks, most fish swam slowly or remained stationary most of the time. During the study the species were kept in a much larger tank (see below) in schools of 4-17 individuals. In this tank all species showed schooling behaviour, and the school size was mainly determined by the availability of the fish and the available space in the net enclosure.

\subsection{Study area}

The experiments were conducted in a large outdoor tank at SEAMARCO's research institute in Wilhelminadorp, The Netherlands. The rectangular tank $(7.0 \mathrm{~m}$ long, $4.0 \mathrm{~m}$ wide; water depth $2.0 \mathrm{~m}$ ) was made of plywood covered on both sides with fibreglass (Fig. 1). The tank was set into a $1 \mathrm{~m}$ deep hole in the ground, resting on a layer of rubber tiles, and the sides below ground level were covered with a layer of $3 \mathrm{~cm}$ thick Styrofoam. The pool walls and floor were blue (Ral colour 50/15).

To reduce predation by birds, algal growth, impact of noise from rain, glistening of the water surface, and to create a more even light pattern in the pool, a slanting roof ( $9 \mathrm{~m} \mathrm{x} 6 \mathrm{~m}$ ) made of Polyurethane between 2 sheets of metal was built above the pool (1.5 m above the water level on one side and $2.0 \mathrm{~m}$ on the other side). From October to December inclusive, artificial lighting was used during the first session of the day.

The water was pumped continuously from the nearby Oosterschelde (a lagoon of the North Sea). The turnover rate of water in the tank was once per day. The salinity was 30- 33 $\%$. To ensure the good water clarity needed to film the fish, the water was circulated via sand, UV light, and carbon filters. Water temperature was measured daily and remained well within the boundaries suitable for the fish species (Table 2). No influence of water temperature on the effects of the stimuli were observed in any of the species; a previous study (Kastelein et al., 2007) also showed that within the temperature range experienced in the present study, the fish reacted to sound independently of the temperature.

To make the environment inside the tank as quiet as possible, the filter unit had a low noise "whisper" pump. To reduce contact noise entering the pool, the pump and filter unit were placed on rubber tiles, and the filtration pump was connected to the tank with flexible tubes.

To ensure that during test sessions all fish could be filmed at any time with one or more (depending on the school length and width) of the three cameras, and to make a change in fish species easy for the fish and the researchers, the fish were kept in a net enclosure $(4 \mathrm{~m}$ 
long, $1.9 \mathrm{~m}$ wide and $2.5 \mathrm{~m}$ high) that was rigged over the width of the tank (Fig. 1). The net was made of white nylon (1.5 cm stretched mesh). By means of lead lines and four weights in the corners, the enclosure kept its rectangular shape. Two research cabins were placed $2 \mathrm{~m}$ apart on one side of the tank. One housed the sound generation equipment, three monitors, video recording equipment, and sound recording equipment. The other housed the sound calibration equipment.

\subsection{Stimuli}

The fish were subjected to pure tones at the following frequencies: $0.1,0.125,0.250$, $0.4,0.5,0.6,0.7,0.8,0.9,1,2,4,8,16,32,45$, and $64 \mathrm{kHz}$. These are mainly octave frequencies, but extra frequencies were tested below $1 \mathrm{kHz}$. The lowest frequency $(0.1 \mathrm{kHz})$ was determined by the equipment available for this study. The stationary portion of all signals was $900 \mathrm{~ms}$ in duration. Rise and fall times (each $50 \mathrm{~ms}$ ) preceded and followed the stationary portion, to prevent abrupt signal onset and offset transients. The tones were produced by a generator (Hewlett Packard, model 33120A), a signal shaper and attenuator (a modified audiometer, Midimate model 602; 5-dB steps), a power amplifier (HQ Power, model VPA2200BMN-2 × $200 \mathrm{~W}$, rms), and one of the following three underwater transducers, depending on the frequency of the projected sounds: for signals of $0.1-0.250 \mathrm{kHz}$, an Ocean Engineering Enterprise transducer (model DRS-12; $30 \mathrm{~cm}$ diameter) and its impedance matching transformer; for signals of $0.4-45 \mathrm{kHz}$, an Ocean Engineering Enterprise transducer (model DRS-8; $20 \mathrm{~cm}$ diameter) and its impedance matching transformer; for 64 $\mathrm{kHz}$ signals, an Airmar high frequency experimental transducer.

During a pre-test with each fish species, the signal levels for the main study were determined by increasing the sound pressure level of each frequency until a reaction, which was best described as a startle response, to the stimulus was observed. That sound pressure level was tested in the main study, as were levels $5 \mathrm{~dB}$ higher and lower. Some signal frequencies caused no reaction when produced at the highest sound pressure level that could be generated with the available equipment. In such cases, that maximum producible level was used during the main study.

During test sessions the audible stimuli and background noise were checked with a hydrophone (Labforce 1 BV, model 90.02.01), a charge amplifier (Brüel \& Kjaer (B\&K), 2635 ) and an amplified loudspeaker. For sounds above $16 \mathrm{kHz}$, the loudspeaker was replaced by a heterodyne frequency reducer (Stag Electronics, Batbox III). The outputs of the charge amplifier and frequency reducer were fed into the video recorders (via ground loop isolators), so that the behaviour of the fish at the exact times of stimulus presentation could later be analysed.

\subsection{Sound measurements}

Two types of sound measurement were carried out during the experiments: 1) determination of the background noise level in the pool, to check that the stimuli were not masked by background noise; 2) determination of the sound pressure levels (SPLs) at two locations in the net enclosure during sound emissions, to check the distribution of the stimulus sounds in the study area.

The equipment used to measure background noise and stimulus SPLs (up to $45 \mathrm{kHz}$ ) was the same and consisted of a broadband hydrophone (B\&K 8101, 0-100 kHz), a voltage amplifier system (TNO TPD, 0-300 kHz) and a personal computer with spectral analysis software (Cool Edit Pro, Syntrillium Software Corp., USA; sample frequency 11-96 kHz, frequency range $0-48 \mathrm{kHz}, \mathrm{df}=15-115 \mathrm{~Hz}$ ). The whole system was calibrated with a 
pistonphone (B\&K 4223) and a white noise 'insert voltage signal' into the hydrophone preamplifier. Measurements were corrected for the frequency sensitivity of the hydrophone and the frequency response of the measurement equipment.

During the course of the study, background noise levels in the tank were determined several times. Levels were measured in the range $0.020-48 \mathrm{kHz}$ as narrow-band Fast Fourier Transform (FFT) results, and were converted to Power Spectral Density (PSD) levels $(1 \mathrm{~Hz}$ bandwidth), time-averaged over $32 \mathrm{~s}$. The remote location of SEAMARCO's institute had been chosen to minimise mechanical and other sound sources, and so background noise levels were very low: generally below those caused by sea state 1 (spectrum level; very low wind conditions; Wentz, 1962). Above wind force Beaufort 4, the background noise in the tank did rise, so no sessions were conducted under wind force conditions above Beaufort 4.

Stimulus sound levels were measured on five occasions, which were well distributed over the study period. Levels were determined in the area in which the fish usually swam $(0.5$ $\mathrm{m}$ above the bottom in the centre of the net enclosure), and at distances of 1.5 and $3.5 \mathrm{~m}$ from the sound sources (transducers). Two frequency ranges were applied to measure the sound distribution in the pool: $0.020-0.5 \mathrm{kHz}$ (sample frequency $11.025 \mathrm{~Hz}$ ) and $0.4-48 \mathrm{kHz}$ (sample frequency $96 \mathrm{kHz}$ ). For each stimulus frequency, the spectra of three sound blocks $(900 \mathrm{~ms}$ duration each) were determined (by FFT) and linearly averaged. Because for pure tones the pool was reverberant and there was a frequency cut-off below approximately $0.250 \mathrm{kHz}$, the propagation loss fluctuated considerably and deflected from the ' $20 \log \mathrm{R}$ ' attenuation law. Additional SPL measurements throughout the net enclosure showed that the stimuli levels (depending on frequency) varied at most by $\pm 8 \mathrm{~dB}$ from the average received level (of the 1.5 $\mathrm{m}$ and $3.5 \mathrm{~m}$ recordings). This received level range was used to calculate the average $50 \%$ reaction threshold as a range, rather than a line. Most stimuli showed no harmonics, and those that did, had harmonics at least $30 \mathrm{~dB}$ below the level of the fundamental frequency.

The $64 \mathrm{kHz}$ signal was calibrated with a calibrated hydrophone (RESON, TC 4032, S/N 1704048), connected to an input module (RESON EC 6073) to transfer the signals to a computer and to power the hydrophone. A battery-powered amplifier (ETEC A1101) was used to condition the hydrophone signal and as a high-pass filter of $10 \mathrm{~Hz}$. As the gain characteristics were flat to $1 \mathrm{MHz}$, a low-pass filter was used on the output of the amplifier to filter the HF noise above $150 \mathrm{kHz}$ with $12 \mathrm{~dB}$ /octave. The output of the filter was connected via a coaxial input module (BNC 2110) to a 16-bit data acquisition card (National Instruments type PCI $6281 \mathrm{M}$ ) on which the analogue signals were digitized with a sample rate of $512 \mathrm{kHz}$. For each data sample the SPL was computed, using the SPL/voltage relation of a pistonphone (G.R.A.S., model 42AC) reference source and a sound level meter (B\&K 2239), to measure the SPL reduction with the hydrophone linked to the pistonphone. With this reference all system errors in the analogue/digital link could be eliminated, assuming a flat response curve of the hydrophone up to $100 \mathrm{kHz}$. The computer with the DAQ card was powered via a UPS (APC 1400) to maintain a floating earth circuit decoupled from the local earth system. The data monitoring/acquisition/analysis functions were conducted by using acoustic software modules developed in Labview 7.0 software (National Instruments) by IMARES. The spectrograms were computed in narrow-band FFT.

\subsection{Observation equipment}

The behaviour of the fish was recorded from above by three black-and-white underwater video cameras (Mariscope, model Micro, Kiel, Germany). The cameras were mounted in a row across the width of the pool (Fig. 1), with the lenses just below the water surface, so that about $80 \%$ of the water volume in the net enclosure was in view. Just below 
the water surface some areas were not in view, but these areas were never used by the fish, which swam near the bottom. The images of the three cameras matched without overlap.

\subsection{Methodology}

In each test a school of fish of only one species was used, in order to avoid the chance of the behaviour of one species influencing the behaviour of another. The $4-17$ fish of each species were placed in the tank at least a day before the first session with that species was conducted. This allowed the fish to habituate to the tank. The transducers and cameras were placed in the pool at the beginning of each working day and remained in the water during all sessions. As the pump in the pool was extremely quiet it was left on during the experiments. Each one-hour session consisted of ten 1-minute trials during which a sound was projected 30 $\mathrm{s}$ after the onset of the trial. The time between trials was 5 minutes. This inter-trial time was based on a pre-test in which the time between signals, at a particular level which caused a startle response when first projected, was reduced from 10 minutes to 1 minute. Often the fish stopped reacting to the individual stimuli when successive signals occurred with only one minute in between, but response was restored after two minutes. Therefore a conservative inter-trial time of five minutes was chosen for the main experiment.

Usually four sessions were conducted daily between 08.30 and $16.00 \mathrm{hrs}$. Per fish species, all frequency and level combinations, determined during the pre-test, were offered in random order during the approximately 15 day study period for that species. Each frequency and level combination was tested 12 times on each fish species (pollack 15 times). The study was conducted between October 2004 and December 2005.

\subsection{Analysis}

Two researchers collected and analysed the data. During the stimulus projection, one researcher (the operator), who could see the entire study area on three monitors in the research cabin, recorded (as a general impression) whether the fish reacted to the stimulus or not. After each session, the reaction of each fish in the school was recorded by the other researcher, from the three video recordings.

A reaction to a stimulus was characterised by a sudden change in swim speed, swim direction and/or body posture during the acoustic signal presentation. If $50 \%$ or more of the fish in the school reacted to the stimulus, the trial was classified as a "reaction" trial. The two researchers alternated tasks between sessions, and when analysing the video recordings, were not aware of the other researcher's previous classification of the trials during the sessions. There was no reason for the researchers to be biased, as we were not expecting or predicting reactions or lack of reactions to any particular sound. The reactions of the fish were in fact so clear that no disagreement between the ratings of the two researchers occurred throughout the study.

Per signal frequency or level combination, the $\%$ of the 12 (15 for pollack) trials in which the fish reacted to the stimulus was calculated. Based on these percentages, psychometric curves were drawn (received level range versus \% reaction). From these curves, the $50 \%$ reaction threshold sound pressure level ranges were derived, and used to draw the upper and lower $50 \%$ reaction threshold curves for each species.

\section{Results}

The fish that responded to the stimuli showed startle responses: they increased their swimming speed and often made tight turns. No startle response was ever seen during test 
periods apart from during signal presentation. In almost all cases when a startle response was seen, the fish swam away from the sound source. The fish always resumed normal swimming behaviour within a few seconds of the end of the $900 \mathrm{~ms}$ acoustic stimulus presentation.

For sea bass, $50 \%$ reaction threshold ranges were reached for signals between 0.1 and $0.7 \mathrm{kHz}$ (Fig. 2A). The sea bass did not react to the maximum received levels that could be produced for the higher frequency signals.

For thicklip mullet, $50 \%$ reaction thresholds were reached for signals between 0.4 and $0.7 \mathrm{kHz}$ (Fig. 2B). The fish did not react to the maximum received levels that could be produced for the other frequencies. However, the mullet reacted to one of the twelve $0.1 \mathrm{kHz}$ signal trials and two of the $0.125 \mathrm{kHz}$ signal trials, which suggests that the $50 \%$ reaction threshold level for those frequencies was only a few $\mathrm{dB}$ above the maximum level that could be produced with the available equipment.

For pout, $50 \%$ reaction thresholds were reached for signals between 0.1 and 0.250 $\mathrm{kHz}$ (Fig. 2C). The pout did not react to the maximum received levels that could be produced for the higher frequency signals.

For Atlantic cod and common eel, no $50 \%$ reaction thresholds could be reached with the maximum levels for the frequencies that could be produced with the available equipment (Figs. 2D and 2E).

For Pollack, no $50 \%$ reaction thresholds could be reached with the maximum levels for the frequencies that could be produced with the available equipment (Fig. 2F). However, there was some reaction to the maximum levels that could be produced for signals of $0.1 \mathrm{kHz}$ (reaction in 4 of the 15 trials), $0.125 \mathrm{kHz}$ ( 4 trials), $0.250 \mathrm{kHz}$ ( 2 trials) and $0.4 \mathrm{kHz}$ (3 trials).

For horse mackerel, $50 \%$ reaction thresholds were reached for signals between 0.1 and $2 \mathrm{kHz}$ (Fig. 2G). The horse mackerel did not react to the maximum received levels that could be produced for the higher frequency signals.

Atlantic herring reacted to two frequencies. The $50 \%$ reaction threshold was reached only for the $4 \mathrm{kHz}$ signal (Fig. 2H). There was also some reaction to the $0.4 \mathrm{kHz}$ signal (in 2 of the 12 trials). The herring did not react to the maximum received levels that could be produced for the other frequencies.

\section{Discussion and conclusions}

We judged that the researchers used consistent criteria for classing a trial as a response trial or a non-response trial, because their classifications were always identical, and the startle response was very obvious (not a subtle increase in swimming speed or swimming depth as was observed in a previous study; Kastelein et al., 2007).

The size of their tank influences the general swimming behaviour of many fish species. Before the fish were put in the test tank, they were kept in much smaller circular tanks, in which they swam very slowly or not at all. In the net enclosure in the large test tank, the fish were much more active; they behaved in the same way as fish in the previous study in this tank, which had the entire tank available to them (Kastelein et al., 2007). So, although the test tank was far from a natural environment, it was a much better study area than the smaller tanks used in several previous studies on reactions of fish to sound.

The study fish had been housed, for at least part of their lives, in tanks at aquaria and fish farms. However, those facilities had water filtration systems that were relatively quiet, so the study animals had probably not been exposed to higher sound levels than wild conspecifics. As the location of the study site was selected because of its remote location and quiet environment, the tank was designed specifically for acoustic research, and the area around the tank was strictly controlled (nobody was present within $100 \mathrm{~m}$ of the tank, except 
the researchers who sat quietly), there was little background noise, and startle responses were not observed outside the signal presentations.

The reactions of the fish in the present study were probably dependent on the context in which the sounds were produced, and the fish probably responded differently than would wild fish. Even in the wild, animals behave differently depending on location, temperature, physiological state, age, body size, and school size. So, even if the present study had been conducted in the wild, the findings may not have been of universal value.

\subsection{Comparison of response threshold levels with hearing threshold levels.}

During recent years, underwater sound has been of growing interest to governments (e.g. National Research Council, 2003), as they have to set standards, for example, for acceptable sound levels for marine animals. However, for convenience, and because of a lack of knowledge, fixed levels above the basic hearing threshold of animals have often been used as criteria for acceptable sound levels (National Research Council, 2005; Southall et al., 2007). Therefore, we compare the response threshold levels we found in the present study to hearing threshold levels, to see if this approach is valid for tones in the fish species tested, and to evaluate the relationship between detection of a sound and response to it.

The hearing sensitivity of only four of the fish species (sea bass, Atlantic cod, pollack, and Atlantic herring) has been tested, either physiologically or behaviourally (Lovell, 2003; Offutt, 1974; Buerkle, 1967; Hawkings and Myrberg, 1983; Chapman and Hawkins, 1973; 1969; Chapman, 1973; Enger, 1967). Although the critical ratios are known only for cod (for $0.06,0.160$ and $0.380 \mathrm{kHz}$ pure tones; Hawkins and Chapman, 1975), it is likely that the background noise level in the tank for these four species was sufficiently low not to mask the test stimuli (Figs. 2A, D, F, and $\mathbf{H}$ ).

Atlantic herring is a hearing specialist. The members of the gadoid family Atlantic cod and pollack (and probably the close relative pout), and the eel, are considered to be hearing generalists with medium hearing ability. Sea bass is believed to be a hearing generalist with higher hearing thresholds. We found no information about hearing in thicklip mullet and horse mackerel.

In the sea bass, the $50 \%$ reaction threshold levels were $0-30 \mathrm{~dB}$ above the hearing thresholds for the test frequencies (ABR audiogram method, Lovell, 2003; Fig. 2A). In the Atlantic cod, which has a gas-filled swim bladder, $50 \%$ reaction threshold levels were not even reached when the test signals were 5-30 dB above the cod's hearing thresholds for those frequencies obtained by Buerkle (1967), who later stated that the hearing was masked by the ambient noise in the tank (Buerkle, 1968; Fig. 2D). Reaction threshold levels were 15-50 dB above the more accepted hearing thresholds obtained for the same species in the ocean by Chapman and Hawkins (1973), and 10-60 dB above those obtained in a physiological audiogram by Offutt (1974; Fig. 2D). Cod have directional hearing (Schuijf and Buwalda, 1975; Hawkins and Sand, 1977). In the wild, directional swimming of cod in response to a sound source has also been observed (Løkkeborg and Soldal, 1993). Although Atlantic cod is considered to have relatively sensitive hearing, it is a species not easily frightened. When a novel object is introduced into a tank, cod investigate it, whereas many other species of fish flee and initially keep a great distance from it. Maybe this bold behaviour caused the animals in the present study not to react to the test signals, even at relatively high levels. On the other hand, avoidance of continuous low frequency pure tones between 0.025 and $0.125 \mathrm{kHz}$ at sound pressure levels of 130 and $140 \mathrm{~dB}$ re $1 \mu \mathrm{Pa}$ was observed in experiments with juvenile and adult cod (C. Mueller-Blenkle, pers. comm.). Cod is sensitive to infrasound down to 0.1 $\mathrm{Hz}$ (Sand and Karlsen, 1986; Enger et al., 1993), so the lack of response in the present study may be because cod is especially sensitive to frequencies lower than those we used. 
In the pollack, $50 \%$ reaction threshold levels were not reached when the test signals were 10-30 dB above the hearing thresholds for the test frequencies obtained by Chapman and Hawkins (1969), and 20-40 dB above the threshold reported by Chapman (1973), although we did see some responses to the $0.1,0.125,0.250$, and $0.4 \mathrm{kHz}$ stimuli (Fig. 2F). This suggests that the $50 \%$ reaction threshold level for those frequencies was only a few $\mathrm{dB}$ above the maximum level that could be produced with the available equipment.

Herring is considered a hearing specialist, as it has a swim bladder that is mechanically coupled to the inner ear, and air-filled vesicles (bullae) close to the inner ear (Enger, 1967). At $4 \mathrm{kHz}$, the $50 \%$ reaction threshold level was $30 \mathrm{~dB}$ above the estimated hearing threshold level for herring (Enger, 1967; Fig. 2H). Blaxter and Hoss (1981) exposed herring to $0.07-0.2 \mathrm{kHz}$ signals, found startle responses at received levels between 122-138 $\mathrm{dB}(\mathrm{re} 1 \mu \mathrm{Pa})$, and observed that the response depended on the size of the herring. Olson (1971) reports that herring showed a clear behavioural response to $0.1 \mathrm{kHz}$ signals when the signal was 20-25 dB above the ambient noise level. Blaxter et al. (1981) found that 2-40 ms signals were sufficient for herring to detect stimuli and localize sound sources. Thus the 900 ms stimuli in the present study were sufficiently long to cause a startle response in herring. As in the present study, herring have been shown to react directionally to sound stimuli in previous studies (Olsen, 1969; Hering, 1969; Schwarz and Greer, 1984).

The present study shows that the difference between the hearing and reaction threshold levels varies per frequency, and within and between the fish species. This suggests that at sea, not only the masking effect of the background noise on a stimulus determines its effect on fish behaviour, but also the frequency spectrum and level of the stimulus. In addition, the present study clearly shows that fish species react very differently to sound, and that generalisations about the effects of sound on fish should be made with the utmost care.

\subsection{Anthropogenic noise}

In the present study only eight of the 224 fish species that occur in the North Sea (Yang, 1982) were tested. Because even within these eight species marked differences in reaction threshold received levels, and in the frequencies that elicited reactions, occurred, it would be useful to conduct similar tests on more fish species and stimuli of different frequency spectra, to be able to predict the reactions of marine fish of the North Sea to anthropogenic noise.

The fish species that responded to sounds in the present study would probably also react to sounds at frequencies lower than those we tested. The lowest frequency tested $(0.1$ $\mathrm{kHz}$ ) was determined by the equipment available for this study. Except for herring, all the fish species that reacted did so to sounds below $2 \mathrm{kHz}$. Some of the reactions to low frequency stimuli in the present study may have been due to particle motion, which was not measured, but should be in future studies of this kind. In general, anthropogenic noise sources have wide spectra, but low frequency parts of the spectra travel further than high frequency parts, so that low frequencies (below $1 \mathrm{kHz}$ ) are dominant at distance from the source (Richardson et al., 1995). Therefore, the fish species tested in the present study could be influenced by anthropogenic activities if tonal signals were produced and if the acoustic received level was above the reaction threshold levels determined in the present study. The received level depends on, among other parameters, the source level of the sound, the water depth, and the propagation loss, which in turn depends on the distance between the sound source and the fish.

In the present study, only the reactions of the fish to pure tones were tested. It would be of interest to test the animals' reaction to sounds more similar to anthropogenic noise, to more complicated sounds, such as sweeps, and to the actual broad-band noise of, for instance, 
wind turbines and shipping, both of which contain pure tones superimposed on a noise spectrum. As well as on the spectrum and level of anthropogenic sounds, the reactions of fish probably depend on the context (e.g. location, temperature, physiological state, age, body size, and school size).

\section{Acknowledgements}

We thank Rob Triesscheijn for all his help during various phases of this project, and Petra van der Marel, Janine Veenstra, Marieke Fennema, and Sonja de Wilde for part of the data collection and analysis. We thank Bert Meijering, director of Topsy Baits, for allowing us the use of his facilities, and Hein Hermans for his help with water quality. We thank Gerard Visser, Michaël Laterveer, and Peter van Putten (all of the Oceanium department of Blijdorp Zoo, Rotterdam), for lending us the Atlantic herring. We thank Christina MüllerBlenkle (Humboldt University, Berlin, Germany) for her comments on an earlier version of this manuscript. This project complied with the Dutch standards for animal experiments, and was funded by the Netherlands Ministry for Agriculture, Nature, and Food Quality (DKWprogram 418: North Sea and Coast). Supervision was done by IMARES, Texel, The Netherlands (via Han Lindeboom and Peter Reijnders).

\section{References}

Astrup, J., Møhl, B., 1993. Detection of intense ultrasound by the cod Gadus morhua. Journal of Experimental Biology, 182, 71-80.

Astrup, J., Møhl, B., 1998. Discrimination between high and low repetition rates of ultrasonic pulses by the cod. Journal of Fish Biology 52, 205-208.

Blaxter, J.H.S., Hoss, D.E., 1981. Startle response in herring: the effect of sound stimulus frequency, size of fish, and selective interference with the acoustico-lateralis system. Journal of the Marine Biology Association U.K. 61, 871-879.

Blaxter, J.H.S., Gray, J.A.B., Denton, E.J., 1981. Sound and startle response in herring shoals. Journal of the Marine Biology Association U.K. 61, 851-869.

Buerkle, U., 1967. An audiogram of the Atlantic cod, Gadus morhua L., Journal of the Fisheries Research Board of Canada 24, 2309-2319.

Buerkle, U., 1968. Relation of pure tone thresholds to background noise level in the Atlantic cod (Gadus morhua). Journal of the Fisheries Research Board of Canada 25, 11551160 .

Chapman C.J. 1973. Field studies of hearing in teleost fish. Helgoländer wissenschaftliche Meeresuntersuchungen, 24, 371-390.

Chapman, C.J., Hawkins, A.D., 1973. A field study of the hearing in cod, Gadus morhua L. Journal of Comparative Physiology 85, 147-167.

Chapman, C.J., Hawkins, A.D., 1969. The importance of sound in fish behaviour in relation to capture by trawls. FAO Fisheries Reports 62, 717-729.

Enger, P.S., 1967. Hearing in herring. Comparative Biochemical Physiology 22, 527-538.

Enger, P.S., Karlsen, H.E., Knudsen, F.R., Sand, O., 1993. Detection and reaction of fish to infrasound. ICES (International Council for the Exploration of the Sea) Marine Science Symposium 196, 108-112.

Hawkins, A.D., 1986. Underwater sound and fish behavior. In: The Behaviour of Teleost Fishes (T.J. Pitcher ed.) Croom Helm, London, 114-151.

Hawkins, A.D., Chapman, C.J., 1975. Masked auditory thresholds in the cod, Gadus morhua L., Journal of Comparative Physiology 103, 209-226. 
Hawkins, A.D., Sand, O., 1977, Directional hearing in the median vertical plane by the cod. Journal of Comparative Physiology 122, 1-8.

Hering, G., 1969. Avoidance of acoustic stimuli by the herring. Int. Counc. Explor. Sea. ICES CM 1969/H:18, pp1-8.

Hughes, K.M., Lehman, L.L., Gearin, P.J., Laake, J. L., DeLong, R.L., Gosho, M.E., 1999. Acoustic alarms and Pacific herring (Clupea pallasi). International Whaling Commission SC/51/SM14.

Kastelein, R. A., van der Heul, S., van der Veen, J., Verboom, W. C., Jennings, N., Reijnders P., 2007. Effects of acoustic alarms, designed to reduce small cetacean bycatch, on the behaviour of North Sea fish species in a large tank. Marine Environmental Research 64, 160-180.

Ladich, F. and A. N. Popper, 2004. Parallel evolution in fish hearing organs. In: Evolution of the Vertebrate Auditory System. G. Manley, A.N. Popper and R.R. Fay (eds). Springer-Verlag, New York. pp. 95 - 227.

Løkkeborg, S., Søldal, A.V., 1993. The influence of seismic exploration with airguns on cod Gadus morhua behaviour and catch rates. ICES (International Council for the Exploration of the Sea) Marine Science Symposium 196, 62-67.

Lovell, J.M. 2003. The hearing abilities of the bass, Dicentrarchus labrax. Technical report commissioned by ARIA Marine Ltd for the European Commission Fifth Framework Programme. Project Reference: Q5AW-CT-2001-01896

Luczkovich, J.J., Daniel III, H.J., Hutchinson, M., Jenkins, T., Johnson, S.E., Pullinger, C., Sprague, M.W., 2000. Sounds of sex and death in the sea: bottlenose dolphin whistles suppress mating choruses of silver perch. Bioacoustics, 10, 323-334.

Mann, D. A., Higgs, D. M., Tavolga, W. N., Popper, A. N., 2002. Ultrasound detection by clupeiforme fishes. Bioacoustics, 12,188-191.

Mann, D.A., Popper, A.N., Wilson, B., 2005. Herring do not detect ultrasound. Proceedings of the Royal Society of London Biological Letters 1, 158-161.

Moulton, J.M., Backus, R.H., 1955. Annotated references concerning the effects of man-made sounds on the movements of fishes. Fisheries Circulation of Department of Seashore Fisheries 17, 1-8.

Myrberg, Jr. A.A., 1990. The effects of man-made noise on the behavior of marine animals. Environment International 16, 575-586.

National Research Council, 2003. Ocean Noise and Marine Mammals. The National Academic Press, Washington D.C., pp 192.

National Research Council, 2005. Marine Mammal Populations and Ocean Noise, Determining when Noise causes Biologically Significant Effects. The National Academic Press, Washington D.C., pp 126.

Offutt, G.C., 1974. Structures for the detection of acoustic stimuli in the Atlantic cod, Gadus Morhua. Journal of the Acoustical Society of America 56, 665-671.

Olsen, K., 1969. Directional responses in herring for sound and noise stimuli. Coun. Meet. International Council for Exploration of the Sea (B.20), 1-8.

Olsen, K., 1971. Influence of vessel noise on behaviour of herring. In: Modern Fishing Gear of the World: 3 (Ed. H. Kristjonsson), Fishing News LTD, London, 291-294.

Popper, A. N., Fay, R. R, Platt, C, and Sand, O. 2003. Sound detection mechanisms and capabilities of teleost fishes. In: Collin, S. P. and Marshall, N. J. (Eds.). Sensory Processing in Aquatic Environments. Springer-Verlag, New York, pp. 3-38.

Popper, A.N., Fewtrell, J., Smith, M.E., and McCauley, R.D., 2004. Anthropogenic sound: Effects on the behavior and physiology of fishes. Marine Technology Soc. J. 37(4):3540.

Richardson, W. J., Greene, C. R., Malme, C. I., Thomson, D. H., 1995. Marine 
Mammals and Noise. Academic Press, London.

Sand, O., Karlsen, H.E., 1986. Detection of infrasound by the Atlantic cod. Journal of Experimental Biology 125, 449-460.

Schuijf, A., Buwalda, R.J.A., 1975. On the mechanism of directional hearing in cod (Gadus morhua L.), Journal of Comparative Physiology 98, 333-343.

Schwartz, A.L., Greer, G.L., 1984. Responses of Pacific Herring, Clupea harengus pallasi, to some Underwater Sounds. Canadian Journal of Fisheries and Aquatic Sciences 41, 1183-1192.

Southall, B. L., Bowles, A.E., Ellison, W.T., Finneran, J.J., Gentry, R.L, Greene Jr., Ch.,Kastak, D., Ketten, D.R., Miller, J.H., Nachtigall, P.E., Richardson, W.J., Thomas, J.A., and Tyack, P.L., 2007. Marine Mammal Noise Exposure Criteria. Aquatic mammals. vol 33, issue 4.

Wentz, G.M., 1962. Acoustic ambient noise in the ocean: spectra and sources. Journal of the Acoustical Society of America 34, 1936-1956.

Wilson, B., Dill, L.M., 2002. Pacific herring respond to simulated odontocete echolocation sounds. Canadian Journal of Fisheries and Aquatic Sciences 59, 542-553.

Yang, J., 1982. The dominant fish fauna in the North Sea and its determination. Journal of Fishery Biology 20, 635-643. 


\section{Tables:}

Table 1. Mean standard body length of the study fish. $\mathrm{N}=$ number of individuals used in the test, $\mathrm{SD}=$ standard deviation. Because herring cannot be touched without damaging them, their body length was estimated.

\begin{tabular}{|l|r|r|r|r|}
\hline Species & N & \multicolumn{3}{|c|}{ Standard body length $(\mathrm{cm})$} \\
\hline & & Mean & SD & Range \\
\hline Sea bass & 17 & 23 & 2.4 & $18-26$ \\
\hline Thicklip mullet & 11 & 17 & 5.3 & $8-24$ \\
\hline Pout & 9 & 21 & 2.7 & $18-24$ \\
\hline Atlantic cod & 5 & 44 & 1.7 & $42-46$ \\
\hline Common eel & 10 & 46 & 6.5 & $35-57$ \\
\hline Pollack & 4 & 24 & 2 & $22-26$ \\
\hline Horse mackerel & 13 & 4 & 0.8 & $3-5$ \\
\hline Atlantic herring & 4 & 27 & - & $25-30$ \\
\hline
\end{tabular}


Table 2. Water temperature during the test periods for each fish species. $\mathrm{N}=$ number of measurements, $\mathrm{SD}=$ standard deviation.

\begin{tabular}{|l|r|r|r|r|}
\hline Fish species & $\mathrm{N}$ & \multicolumn{3}{|c|}{ Water temperature $\left({ }^{\circ} \mathrm{C}\right)$} \\
\hline & & Mean & SD & Range \\
\hline Sea bass & 9 & 8.7 & 1.0 & $7-10$ \\
\hline Thicklip mullet & 9 & 6.9 & 0.8 & $6-8$ \\
\hline Pout & 9 & 5.3 & 1.2 & $4-7$ \\
\hline Atlantic cod & 15 & 8.1 & 0.8 & $7-9$ \\
\hline Common eel & 7 & 6.1 & 0.7 & $5-7$ \\
\hline Pollack & 28 & 10.2 & 2.9 & $6-16$ \\
\hline Horse mackerel & 15 & 14.4 & 1.2 & $13-16$ \\
\hline Atlantic herring & 6 & 9.3 & 0.5 & $9-10$ \\
\hline
\end{tabular}


Fig. 1. A schematic view of the study area, showing the tank, the net enclosure, the location of the three cameras, and the three transducers. The fish are shown to scale for the larger fish species.

Fig. 2. The maximum received level range that could be produced in the tank for the test frequencies causing no reactions, and, for some species, the $50 \%$ reaction SPL ranges (shaded areas represent $\pm 8 \mathrm{~dB}$ of average received level).

A) Sea bass (0.1-0.7 kHz; school size: $17 \mathrm{fish}$ ), and the background noise range in the net enclosure, which applies to all species. Also shown is the auditory brainstem response (ABR) audiogram of sea bass.

B) Thicklip mullet $(0.4-0.7 \mathrm{kHz}$; school size: 11 fish).

C) Pout (0.1-0.250 kHz; school size: 9 fish).

D) Atlantic cod (school size: 5 fish). Also shown are three hearing thresholds of Atlantic cod.

E) Common eel (school size: 10 fish).

F) Pollack (school size: 4 fish). There was some reaction $(<50 \%)$ to the maximum levels that could be produced for signals of $0.1 \mathrm{kHz}, 0.125 \mathrm{kHz}, 0.250 \mathrm{kHz}$ and $0.4 \mathrm{kHz}$. Also shown are two hearing thresholds of pollack.

G) Horse mackerel (0.1-2 kHz; school size: 13 fish).

$\mathrm{H})$ Atlantic herring ( $4 \mathrm{kHz}$; school size: 4 fish). Also shown is the hearing threshold of Atlantic herring. 
Figure 1

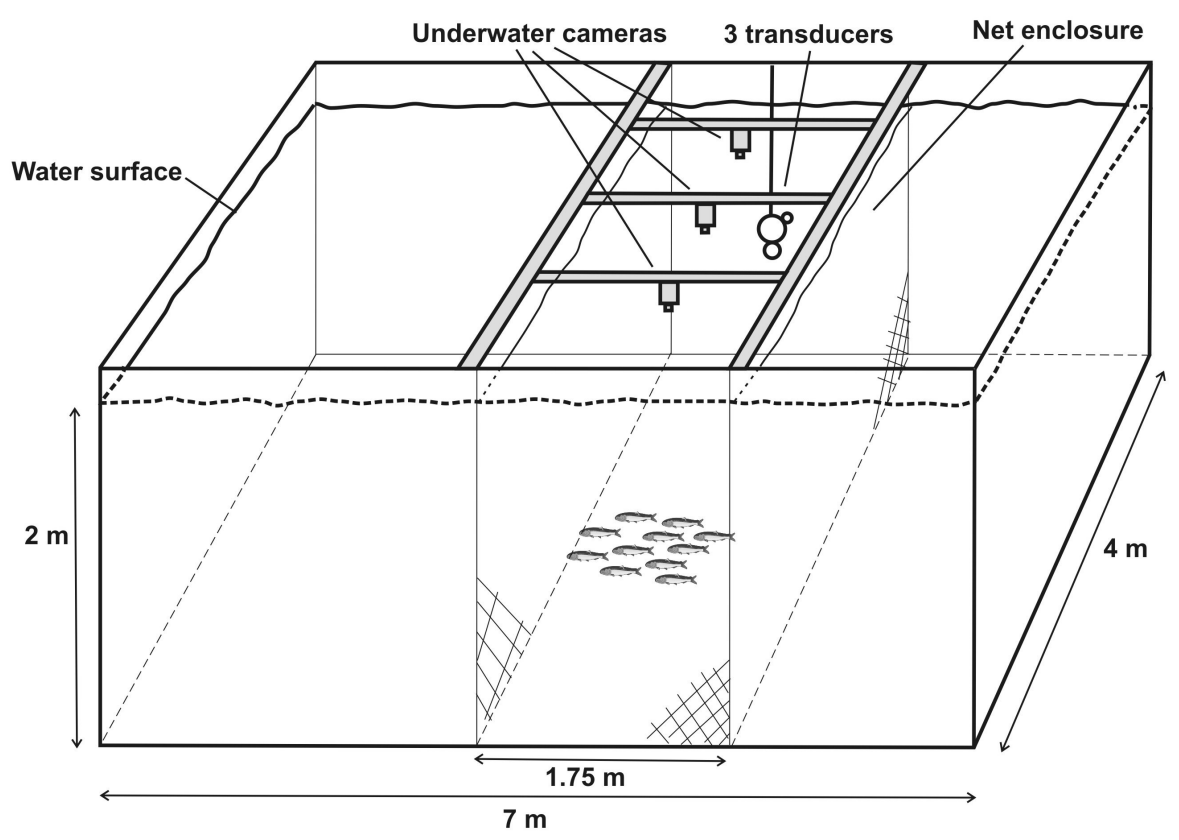




\section{Figure 2a}

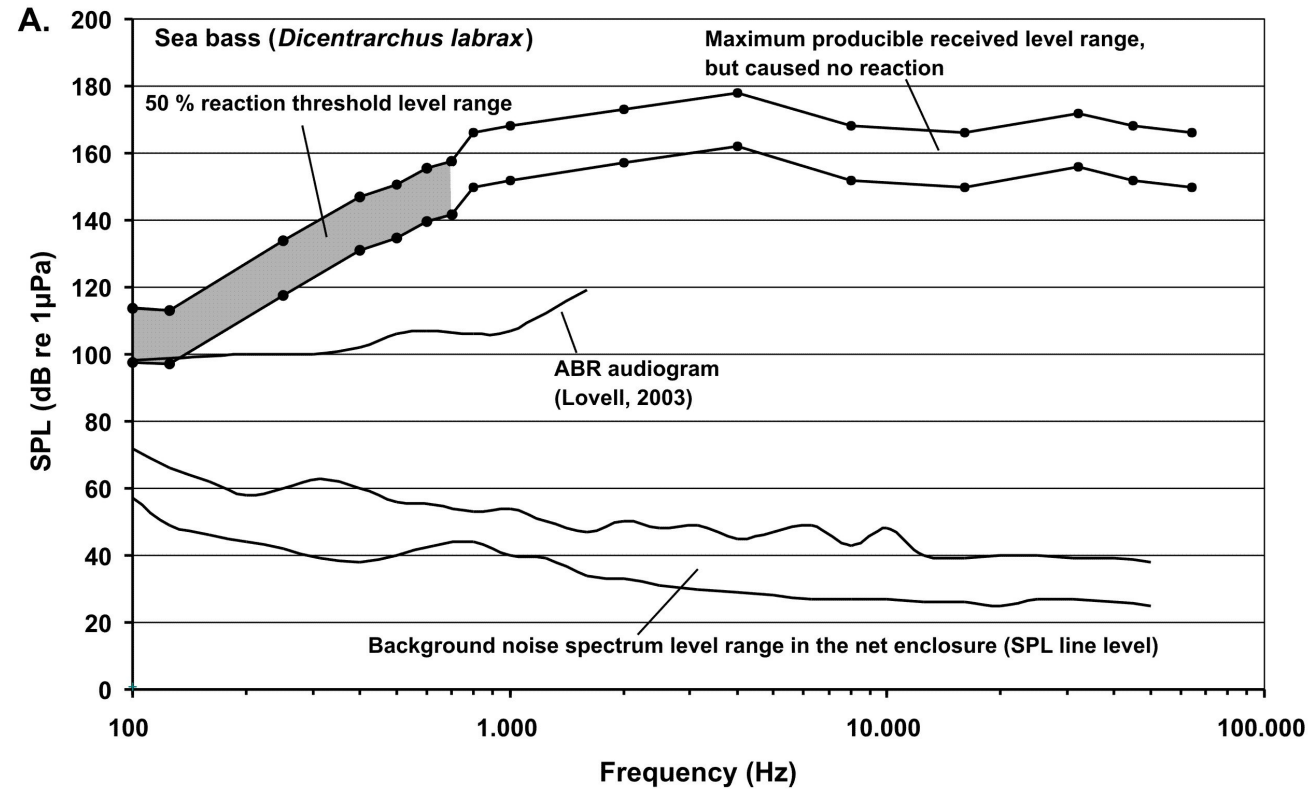




\section{Figure $2 b$}

Fish dose response

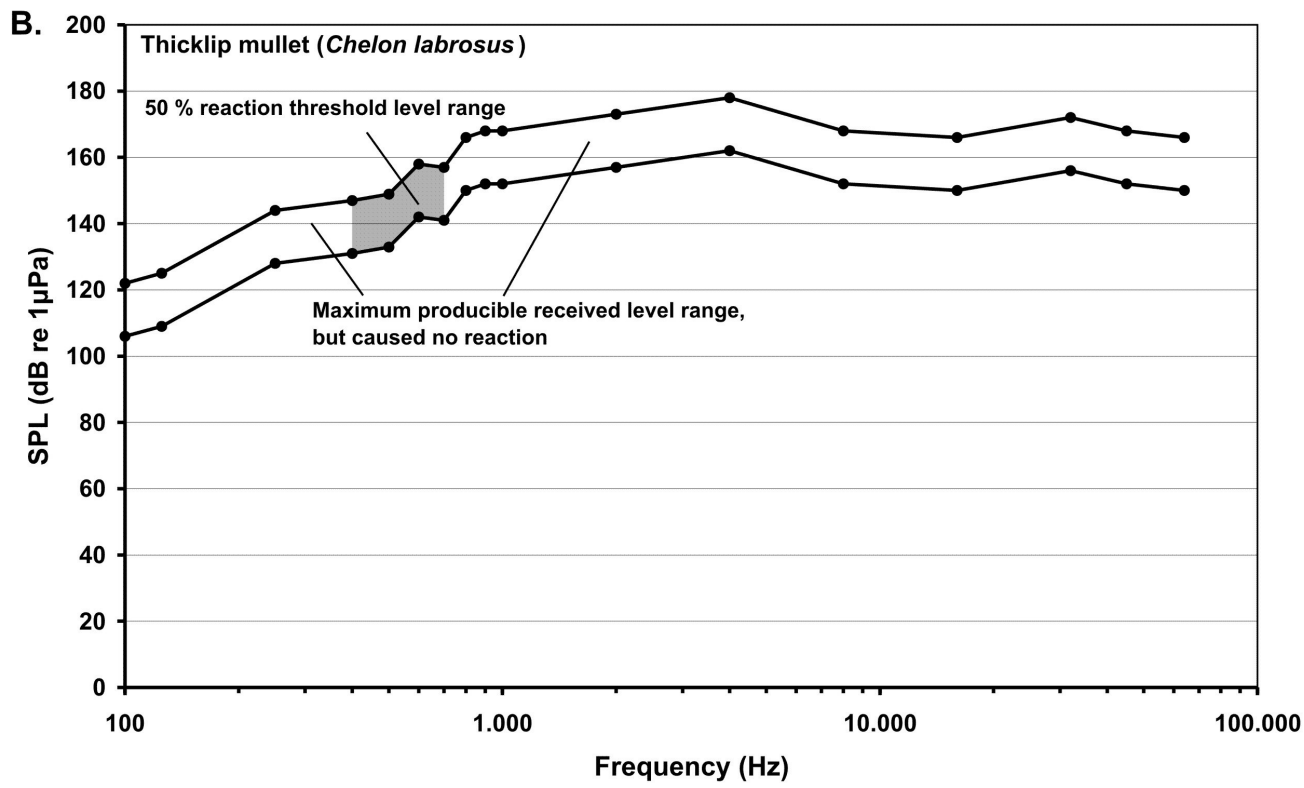


Figure 2c

Fish dose response

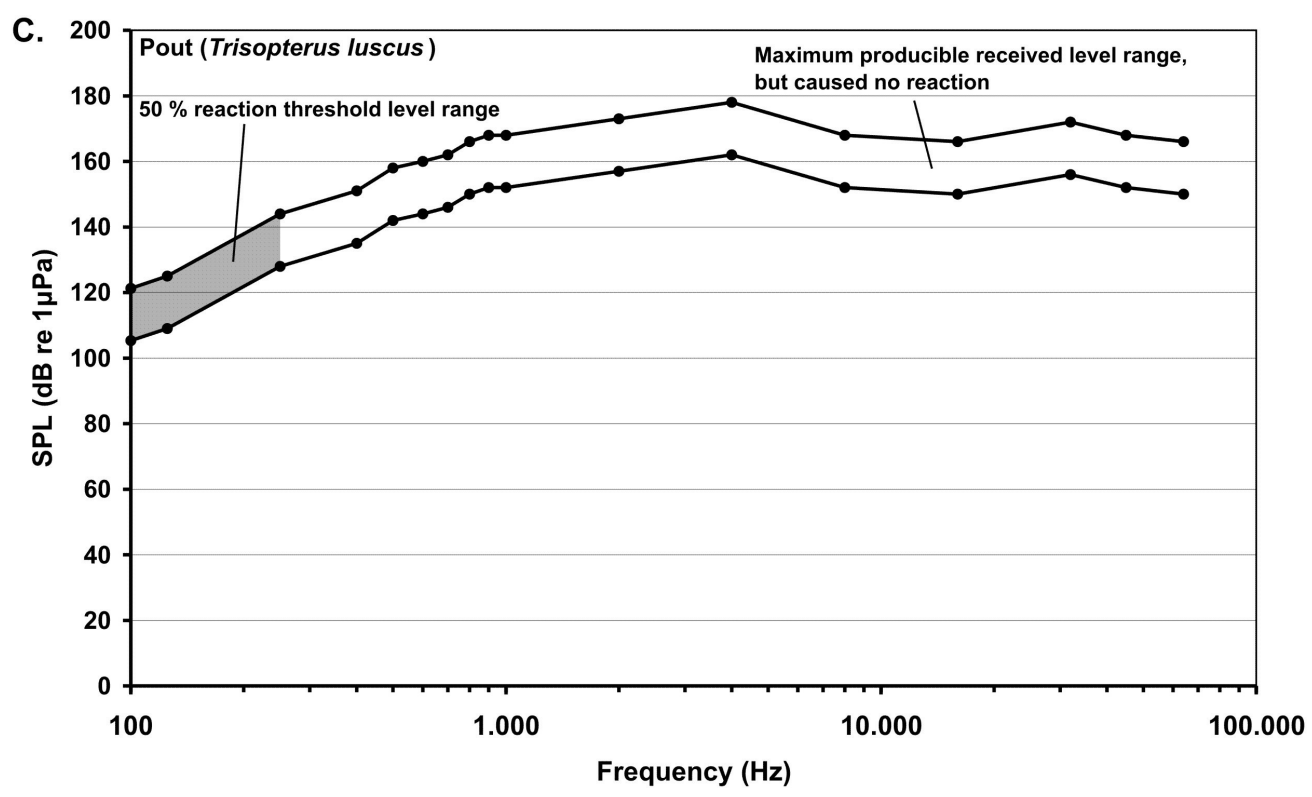




\section{Figure 2d}

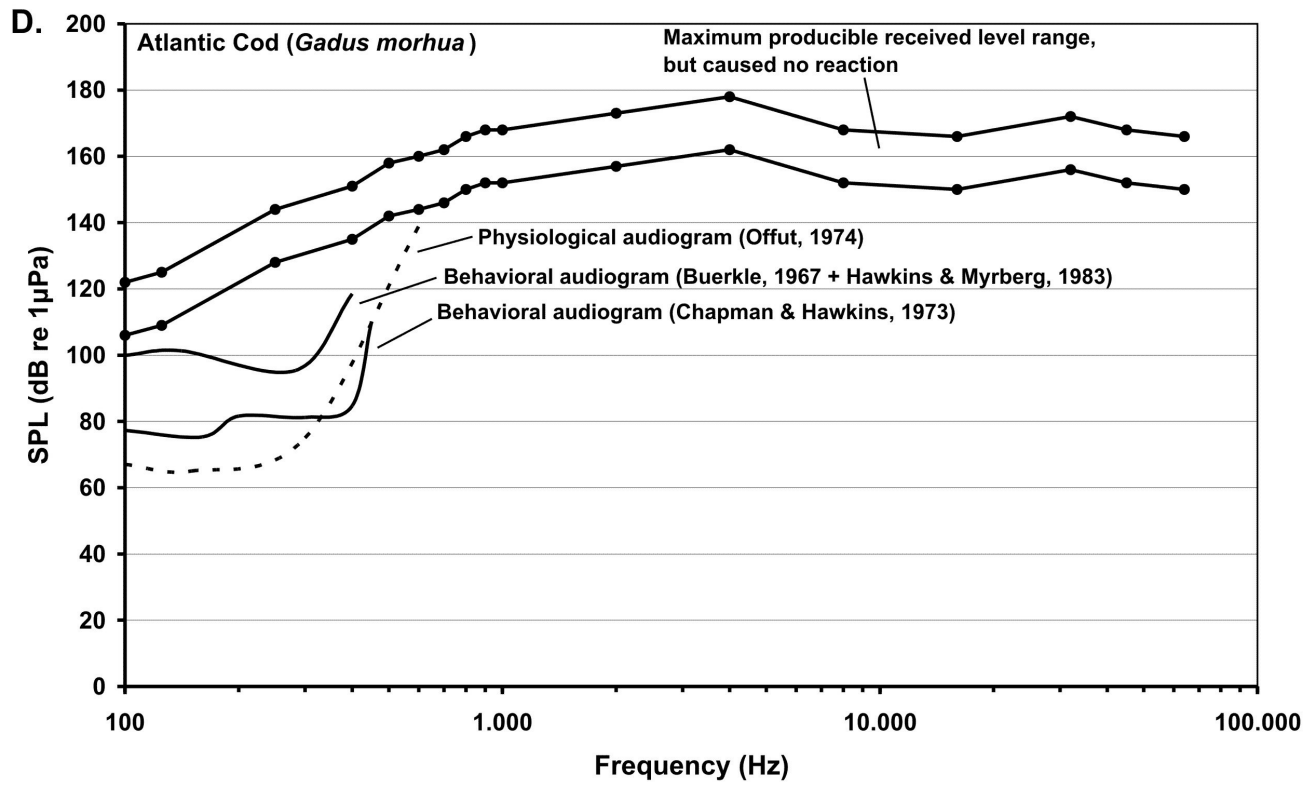


Figure 2e

Fish dose response

Figure 2e

21-12-2007/11:18

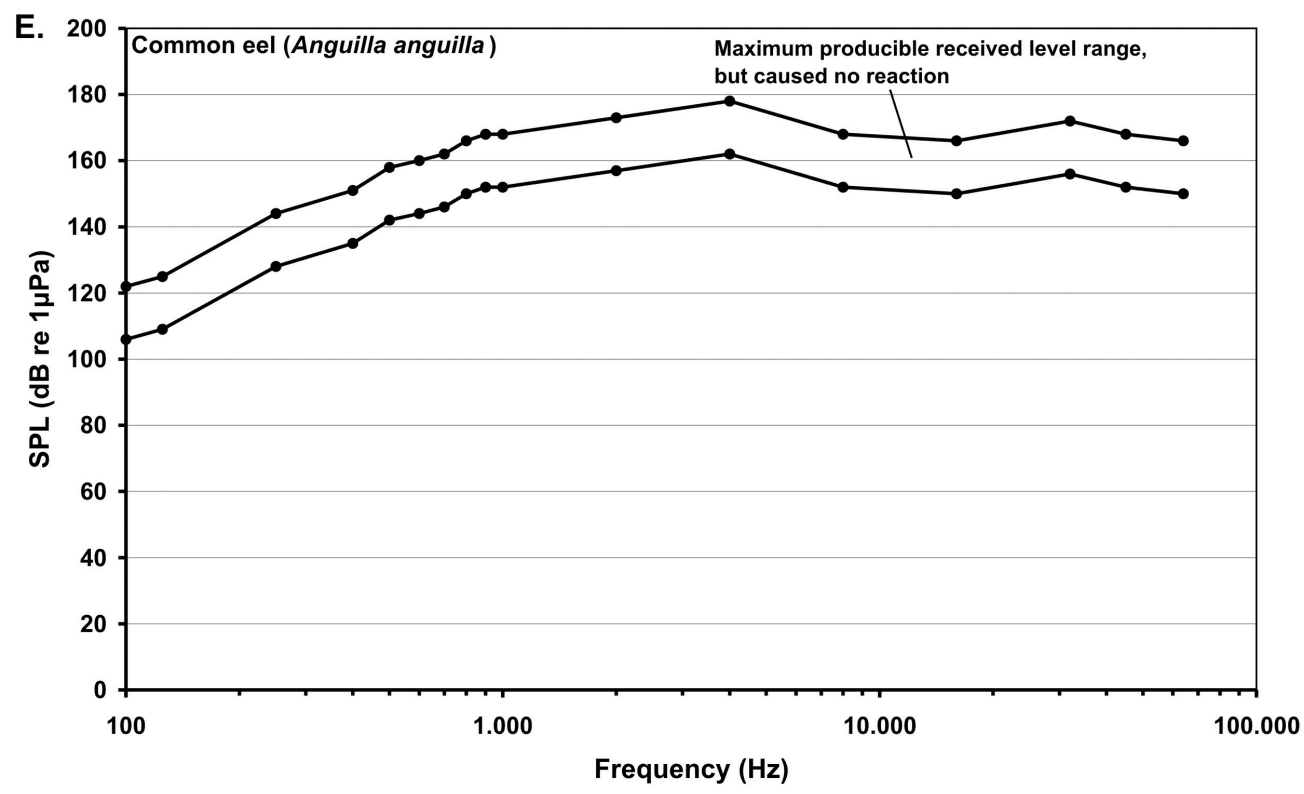




\section{Figure $2 f$}

Fish dose response

Figure $2 f$

21-12-2007/11:14

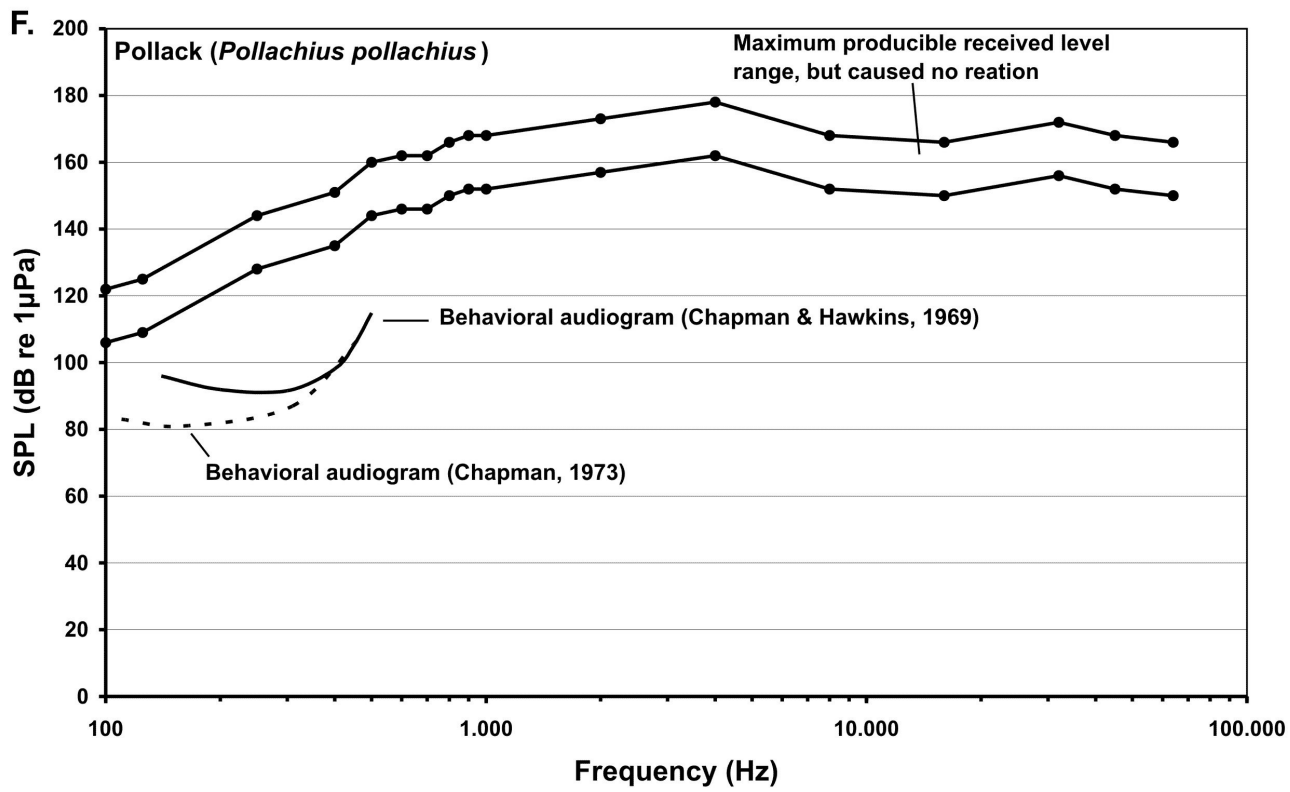


Reactions to sound by North Sea fish

Kastelein et al.

Figure 2g

Fish dose response

Figure $2 g$

21-12-2007/11:04

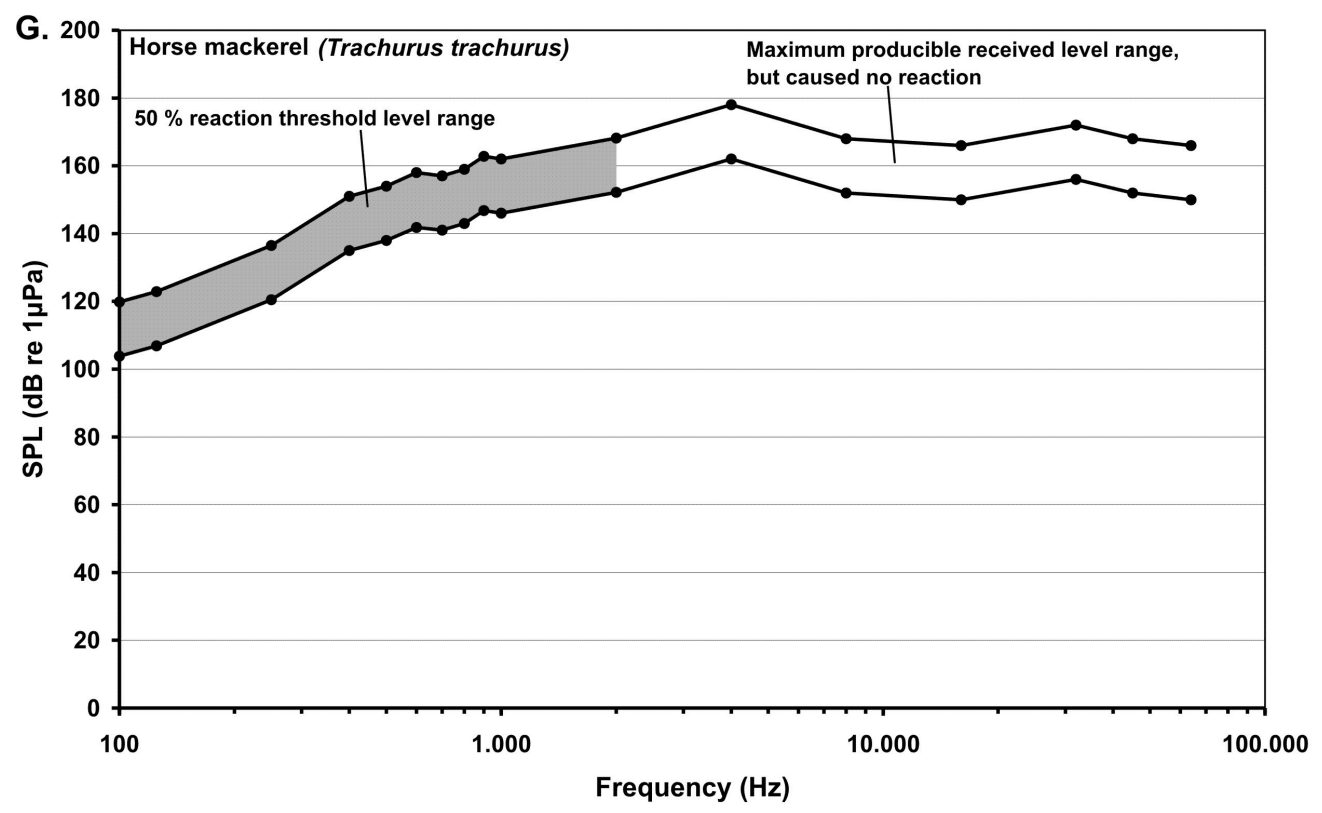




\section{Figure $2 \mathrm{~h}$}

Fish dose response

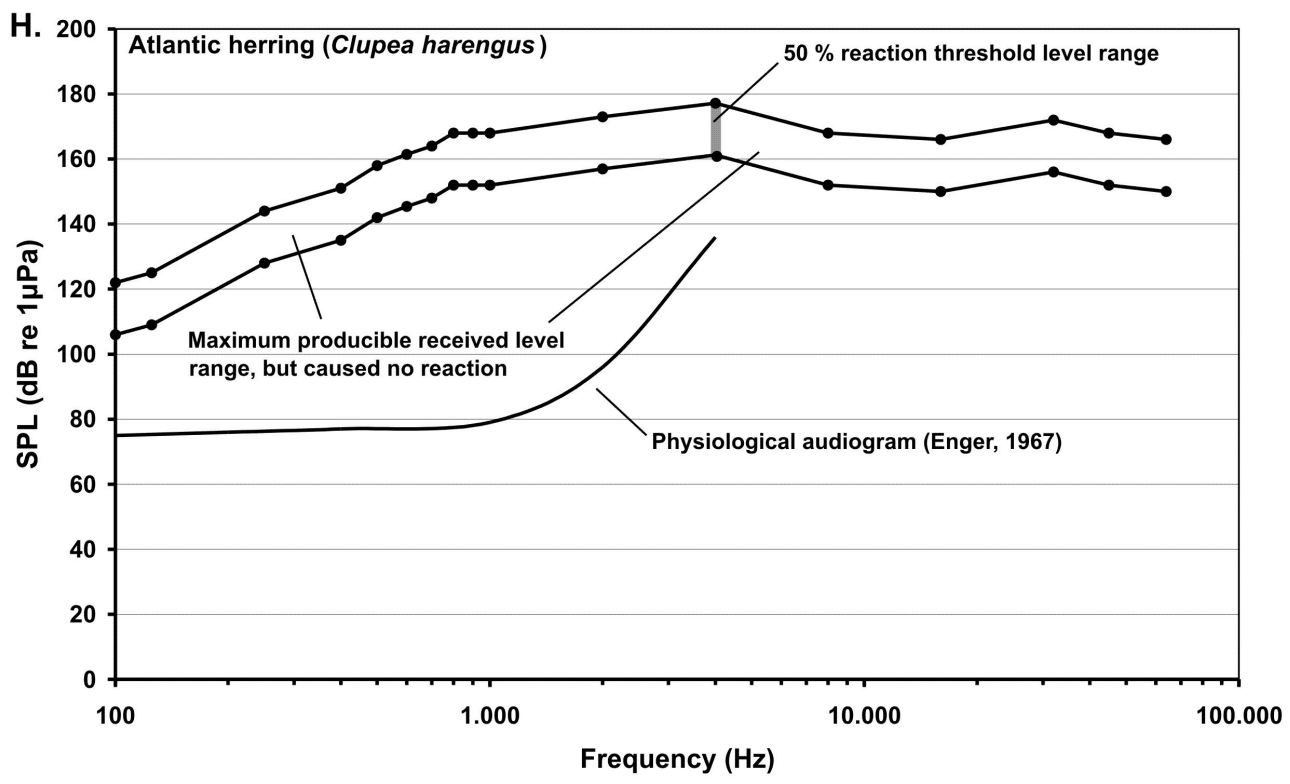

